\title{
SPECIFIC AND NON-SPECIFIC BINDING OF AN ORGANOPHOSPHATE SPIN LABEL TO SOME SERINE-ESTERASES
}

\author{
A.J. HOFF* \\ Laboratory of Physiological Chemistry, University of Leiden, The Netherlands \\ R.A. OOSTERBAAN \\ Medical Biological Laboratory TNO, Rijswijk Z.H., The Netherlands \\ and \\ R. DEEN \\ Central Laboratory TNO, Delft, The Netherlands \\ Received 4 February 1971
}

\section{Introduction}

Spin labelling has become an important tool in probing the structure of biological materials. Recently organophosphate spin labels have been described which were reported to react specifically with the serine residue in the active site of serine-esterases $[1,2]$. This offers the possibility of comparing the spatial structure surrounding the active serine in these enzymes. In this paper the results are given of an ESR study on a bacterial atropinesterase [3], on subtilisin and on chymotrypsin, which were reacted with the organophosphate spin label 1-oxyl-2,2,6,6-tetramethyl-4-piperidinyl methylphosphonofluoridate. It was found that this spin label to some extent also bound non-specifically to subtilisin and chymotrypsin, making a detailed comparison of the ESR spectra of these enzymes with that of atropinesterase difficult. This non-specific binding could be largely suppressed by modifying the experimental conditions. The spectra then found differed only slightly for the three enzymes. They were typical for almost totally immobilized spin label.

\footnotetext{
* Present address: Medical Biological Laboratory TNO, 139 Lange Kleiweg, Rijswijk Z.H., The Netherlands.
}

\section{Materials and methods}

Subtilisin was purchased from NOVO Industri A/S, chymotrypsin from Nutritional Biochemical Corporation. Atropinesterase was isolated from Pseudomonas putida and purified as described elsewhere [3] . All enzymes were pure as judged from polyacrylamide gel-electrophoresis SDS and urea.

The phosphonate spin label was prepared according to Morrisett, Broomfield and Hackley [1] . The starting material 1-oxyl-2,2,6,6-tetramethylpiperidinol-4 was synthesized according to Brière, Lemaire and Rassat [4]. The product was digested with $\mathrm{CCl}_{4}$ and further purified by recrystallization, giving orange crystals ( $\mathrm{mp} 69^{\circ}$, correct elementary analysis and IR spectrum). The phosphonate

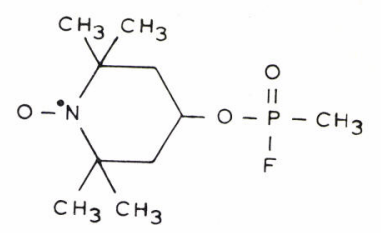

was purified by molecular distillation ( el. analysis P 12.68, F 7.05; calc. 12.28 and 7.53 resp.; correct IR spectrum). The ESR signal consisted of the usual three lines with a partly resolved proton hyperfine structure. 


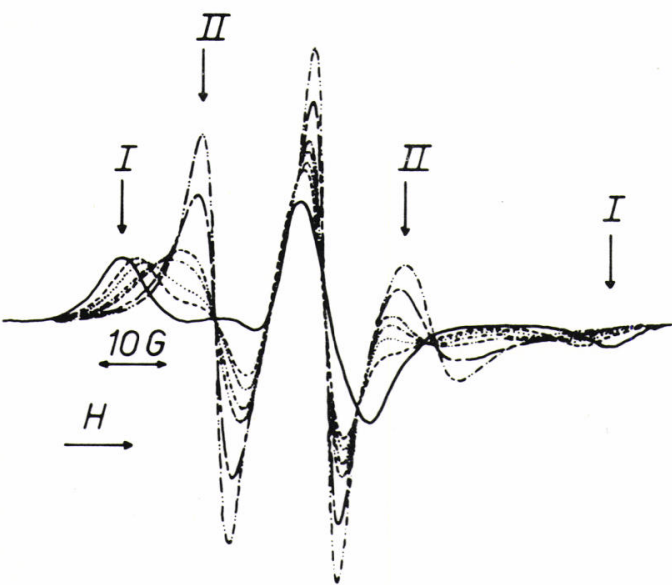

Fig. 1. ESR spectra of $0.16 \mathrm{mM}$ 1-oxyl-2,2,6,6-tetramethylpiperidinol-4 in a mixture of $53 \%$ glycerol in water at different temperatures. Gain 100, modulation $2 \mathrm{G}$, power $10 \mathrm{~mW}$. Arrows labelled I and II indicate features characteristic of strongly and weakly immobilized spin label respectively. $(-\cdot-)) 0^{\circ}, \tau_{\mathrm{c}}=$ $4.5 \mathrm{nsec} ;(---)-4^{\circ}, 6 \mathrm{nsec} ;(-. .-)-10^{\circ}, 9 \mathrm{nsec} ;(-. .-)-12^{\circ}$, $12 \mathrm{nsec} ;(. \ldots)-14^{\circ}, 30 \mathrm{nsec} ;(-\ldots)-.20^{\circ}, 60 \mathrm{nsec} ;(-\longrightarrow)$ $-74^{\circ}, 120$ nsec.

Enzyme solutions of around $0.1 \mathrm{mM}$ in $10 \mathrm{ml} 0.02$ $\mathrm{M}$ tris- $\mathrm{HCl}$ buffer of $\mathrm{pH} 8.3$ were treated at $25^{\circ}$ with a solution of $0.1 \mathrm{M}$ spin label in isopropanol. To remove free label the mixture was extensively dialysed at $4^{\circ}$ against the tris buffer with $0.1 \mathrm{M} \mathrm{KCl}$ added and then concentrated about 10 times by ultradialysis. In some experiments the excess free label was removed by gel-filtration at $4^{\circ}$ on Sephadex G50 in the high salt buffer. As a control the enzymes were completely inhibited at $25^{\circ}$ by excess DFP (diisopropyl phosphorofluoridate), dialysed in the cold against the high salt buffer, subsequently dialysed against the tris buffer without $\mathrm{KCl}$ and then treated with spin label as above. Between successive steps preparations were kept at $0^{\circ}$, samples were stored at $-18^{\circ}$. After each step and after the ESR measurements the preparations were tested for recovery of enzyme activity by spontaneous dephosphorylation. This proved not to occur under the experimental conditions. Enzyme activity was determined by conventional $\mathrm{pH}$-stat method using $N$-acetyl-L-tyrosine ethyl-ester and (-)-atropine as substrates.

ESR spectra of the enzyme preparations were measured at $0^{\circ}$ with a JEOLCO ME-IX spectrometer. Thin glass capillaries containing the samples were cen- tred along the axis of the cylindrical cavity. Reference spectra were obtained by recording the spectrum of a sample of the oxyltetramethylpiperidinol dissolved in a glycerol-water mixture over a range of temperatures (fig. 1). The shape of the ESR spectrum of the spin label, which reflects its freedom of motion, was characterized by the correlation time $\tau_{c}$. The values of $\tau_{c}$ were based on the estimation of Hsia and Piette [5] for the same radical in glycerol-water mixtures. Although the absolute values of $\tau_{c}$ are not reliable, the method is adequate for qualitative comparison. Since the reference spectra were measured on one and the same sample, they could be used to relate the height of lines at various correlation times with the amplitudes of the completely isotropic spectrum. In this way the concentration ratios of isotropic and anisotropic components in mixed spectra were determined.

\section{Results and discussion}

The spin label proved a very effective inhibitor for subtilisin, chymotrypsin and atropinesterase, the $k_{\mathrm{I}}$ being approximately $3 \times 10^{4}, 1 \times 10^{5}$ and $2 \times 10^{4} \mathrm{M}^{-1} \mathrm{~min}^{-1}$ respectively.

The spectrum of spin-labelled atropinesterase is given in fig. 2a. It has the shape of the anisotropic, broadened spectrum typical for strongly immobilized label. Superimposed is a minor component, characteristic of weakly immobilized label. This minor component amounts to less than one percent of the total spin concentration. Since the enzyme is completely inhibited the anisotropic spectrum, designated type I, must be due to spin label which is specifically bound to the active serine. The mobility of the label depends on the tertiary structure of the enzyme, as is demonstrated by the ESR spectrum of the same sample, after denaturation with $4.5 \mathrm{M}$ urea (fig. 2b), showing an increased mobility as expected.

The ESR spectra of completely inhibited subtilisin and chymotrypsin differ markedly from that of labelled atropinesterase (fig. $2 \mathrm{c}$ and d). Here the isotropic spectrum (type II), typical for weakly immobilized label, is much more prominent. Consequently in both spectra the low field region of the anisotropic component is distorted, which hampers detailed comparison of this component with the atropinesterase spectrum. 


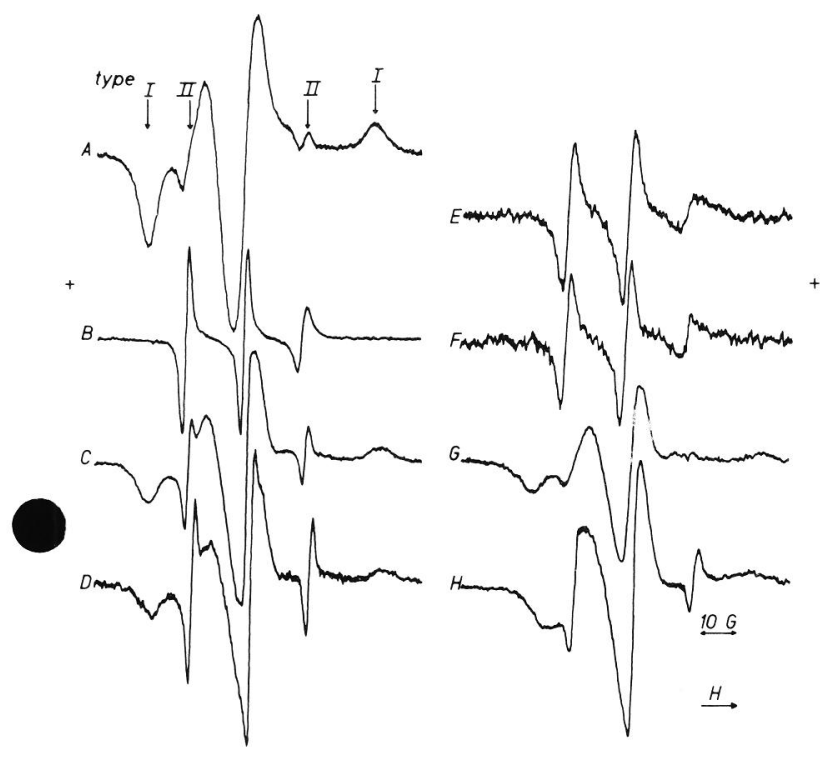

Fig. 2. ESR spectra of spin-labelled atropinesterase, subtilisin and chymotrypsin.

a) $0.5 \mathrm{mM}$ atropinesterase labelled during $60 \mathrm{~min}$ with $2.0 \mathrm{mM}$ spin label at $25^{\circ}$ to $99.0 \%$ inhibition

b) atropinesterase from a) denatured with $4.5 \mathrm{M}$ urea

c) $0.18 \mathrm{mM}$ subtilisin labelled for $40 \mathrm{~min}$ with $0.5 \mathrm{mM}$ spin label at $25^{\circ}$ to $99.5 \%$ inhibition

d) $0.4 \mathrm{mM}$ chymotrypsin labelled for $30 \mathrm{~min}$ with $2.0 \mathrm{mM}$ spin label at $22^{\circ}$ to $99.3 \%$ inhibition

e) and f) $0.07 \mathrm{mM}$ subtilisin and $0.1 \mathrm{mM}$ chymotrypsin respectively, inhibited for $15 \mathrm{~min}$ with $1.0 \mathrm{mM} \mathrm{DFP}$ at $22^{\circ}$ to $99.7 \%$ and $99.4 \%$ inhibition respectively, dialyzed first against $0.02 \mathrm{M}$ tris- $\mathrm{HCl}$ buffer $\mathrm{pH} 8.3$ and then against the same buffer with $0.1 \mathrm{M} \mathrm{KCl}$ added, then treated for $15 \mathrm{~min}$ with $0.5 \mathrm{mM}$ spin label at $22^{\circ}$. Gel-filtration on Sephadex G 50 at $0^{\circ}$ in the high salt buffer, and then concentrated 10 times by ultradialysis

g) and h) $0.07 \mathrm{mM}$ subtilisin and $0.1 \mathrm{mM}$ chymotrypsin labelled with 0.04 and $0.05 \mathrm{mM}$ spin label to $57 \%$ and $65 \%$ inhibition respectively, then treated for $30 \mathrm{~min}$ with $1.5 \mathrm{mM} \mathrm{DFP}$ at $22^{\circ}$ to $99.5 \%$ and $99.3 \%$ inhibition respectively. Gel-filtration and concentration as above Spectrometer data: frequency $9.26 \mathrm{GHz}$; field sweep $\pm 50 \mathrm{G}$. mod. width $2 \mathrm{G}$, except b and c: $1 \mathrm{G}$; resp. 0.3 or $1 \mathrm{sec}$, sweep time 5 or $10 \mathrm{~min}$; power $10 \mathrm{~mW}$; gain for $\mathrm{a}-\mathrm{h}$ : $360,560,220,560,790,1000,360$ and 500 respectively

The high intensity of the type II signal in subtilisin and chymotrypsin is rather puzzling. Organophosphate inhibitors usually bind exclusively to the active serine under the conditions of our experiment [6]. Published spectra of esterases labelled with the same spin label as used in this work do not show the complex pattern which we found [1]. The type II signal can not be due to spin label released by reactivated enzyme since before and after the ESR experiments all enzymes were completely inhibited (>99\%) . Moreover, a similar signal was present in the controls consisting of enzymes which were completely inhibited with DFP prior to spin label treatment, as shown in fig. $2 \mathrm{e}$ and $\mathrm{f}$. The correlation time of this signal is $0.2 \mathrm{nsec}$. This indicates that the mobility of the nitroxide group of the spin label is appreciable but not yet as high as that of free label.

Conceivably the type II signal could be due to

1) absorbed, but not covalently bonded spin label,

2) spin label bonded to products of autolysis in the case of subtilisin and chymotrypsin,

3) denaturation of protein after spin labelling,

4) different mobility of the bonded R and S stereoisomers of the spin label, which contains an asymmetric phosphorus atom,

5) reaction of the spin label with non-specific sites, resulting in a weaker immobilization.

In the following the foregoing possibilities are discussed.

The presence of absorbed spin label is unlikely, because extensive dialysis against high salt buffer led to essentially unchanged spectra.

Since autolysis may occur during the period that the proteolytic activity of subtilisin and chymotrypsin is not yet inhibited completely, the formation of labelled protein fragments cannot be excluded a priori. Therefore the experiments were repeated with preparations that had been subjected to gel-filtration on Sephadex G 50 after the inhibition. All proteins were eluted as a single peak as measured by the absorbancy of the fractions at $280 \mathrm{~nm}$. The fractions were pooled in three roughly equal portions, corresponding to the front, centre and last section of the peak, and concentrated by ultradialysis. For subtilisin, which does not contain $\mathrm{S}-\mathrm{S}$ bridges, labelled fragments would be expected to be eluted after the protein peak if autolysis had occurred, whereas for both proteases a different composition of the first and last section of the elution peak might be expected. However, all labelled enzymes showed identical spectra for all three sections of the elution peak, which did not differ from the ones recorded for samples prepared without gel-filtration. Furthermore the intensity of the type II signal did not increase when the labelled enzymes were in- 
cubated for 15 minutes with equal amounts of an active proteolytic enzyme. These results exclude labelled products of autolysis as the source of the type II signal.

In enzymes pretreated with excess DFP, the active site is no longer available for labelling. Accordingly, in the spectra of these preparations the type I signal was not present. Yet, as shown in fig. 2 e and $f$, these samples exhibit a type II spectrum nearly as intense as the samples that were not treated with DFP (fig. $2 \mathrm{c}$ and d). Apparently the type II signal is not due to denaturation of the protein after labelling at the active site.

In some experiments the enzymes were inhibited completely with approximately stoichiometric amounts of spin label. Assuming a different mode of binding for the $\mathrm{R}$ and $\mathrm{S}$ isomers of the spin label, one would expect nearly equal amounts of weakly and strongly immobilized spin label. However, the concentration of spin label giving rise to the type II signal was about one tenth of that of the type I signal, indicating that the presence of the type II spectrum is not due to one of the $\mathrm{R}$ and $\mathrm{S}$ forms of the spin label.

If the type II signal is due to non-specific binding sites, one would expect at least one such site per enzyme molecule. However, from the spectra of fig. $2 \mathrm{c}$ and $d$ it was calculated that the concentration of type II sites is only $7.0 \%$ and $15.2 \%$ of the concentration of the type I sites for subtilisin and chymotrypsin respectively. Prolonged incubation of DFP inhibited subtilisin with excess spin label did not enhance the low concentration of weakly immobilized label. From the data and the known enzyme concentration it was calculated that only about 5 percent of inhibited enzyme molecules possess an accessible non-specific site, which apparently does not react with DFP. In ordinary enzymological work this small fraction will usually remain undetected, but in ESR experimen ts with the sensitive spin label technique it makes interpretation of spectra hazardous unless precautions are taken to reduce its effect.

It was found that the reaction of spin label with the non-specific sites could be suppressed to a large extent by incubating subtilisin and chymotrypsin with a less than stoichiometric amount of spin label. From the spectra obtained (fig. $2 \mathrm{~g}$ and $\mathrm{h}$ ) and from the spectrum of atropinesterase (fig. 2a) the correlation time of the strongly immobilized spin label was determined. For atropinesterase, subtilisin and chymotrypsin it amounted to 37,44 and $15 \mathrm{nsec}$ respectively. These values are approximately equal to the tumbling time of the protein molecules as estimated from the Einstein-Stokes relation (about $20 \mathrm{nsec}$ ), indicating that spin label attached to the active site is almost completely immobilized relative to the protein molecule. This result is in contrast with the data of Morrisett et al. [1], who investigated the binding of the same compound to acetylcholinesterase and to chymotrypsin at $\mathrm{pH} 4$; in both cases the spin label was only partly immobilized relative to the protein.

The lower value of the correlation time for chymo trypsin with respect to those for the other enzymes cannot be explained on the basis of their respective molecular weights, which are only slightly different. It follows that the $-\mathrm{NO}^{\circ}$ group of the spin label has an increased motional freedom at the active site of chymotrypsin. This site is reported to form a pocket or slit whose dimensions are about $11 \AA$ by $6 \AA$ by $4 \AA$ [7] ; presumably the bulky tetramethylpiperidinyl group (diameter about $10 \AA$ ) cannot be accommodated fully in the rather narrow slit, but will protrude partially into the solvent. Apparently the active site of subtilisin and that of atropinesterase is wider and thus the spin label is more fully immobilized in these enzymes. Whether the slight difference in correlation times between subtilisin and atropinesterase is significant will require further investigation.

\section{Acknowledgements}

The authors are indebted to Mr. H.P. Benschop of the Chemical Laboratory RVO-TNO for preparation of the spin label, to Mr. W. 't Jong for ESR measurements and to Dr. F. Berends for the determination of the $k_{\mathrm{I}}$ 's and for stimulating discussion.

\section{References}

[1] J.D. Morrisett, C.A. Broomfield and B.E. Hackley, Jr., J. Biol. Chem. 244 (1969) 5758.

[2] J.C. Hsia, D.J. Kosman and L.H. Piette, Biochem. Biophys. Res. Commun. 36 (1969) 75.

[3] A. Rörsch, F. Berends, W.F. Stevens and H.C. Bartlema, Koninkl. Ned. Akad. Wetenschap. Proc. Ser. C (Proc. Royal Neth. Acad. Sci.) in press. 
[4] R. Brière, H. Lemaire and A. Rassat, Bull. Soc. Chim. France 32 (1965) 3273.

[5] J.C. Hsia and L.H. Piette, Arch. Biochem. Biophys. 129 (1969) 296.
[6] J.A. Cohen, R.A. Oosterbaan and F. Berends, Methods in Enzymology, ed. C.H.W. Hirs, vol. 11 (Acad. Press, New York, 1967) p. 686.

[7] T.A. Steitz, R. Henderson and D.M. Blow, J. Mol. Biol. 46 (1969) 337. 
